Article

\title{
Effect of Trapping Agent and Polystyrene Chain End Functionality on Radical Trap-Assisted Atom Transfer Radical Coupling
}

\section{Elizabeth M. Carnicom, Jessica A. Abruzzese, Yacouba Sidibe, Kenneth D. Myers and}

Eric S. Tillman *

Department of Chemistry, Bucknell University, Lewisburg, PA 17837, USA;

E-Mails: emc027@bucknell.edu (E.M.C.); jaa024@bucknell.edu (J.A.A.); ys010@bucknell.edu (Y.S.); kdm014@bucknell.edu (K.D.M.)

* Author to whom correspondence should be addressed; E-Mail: etillman@bucknell.edu; Tel.: +1-570-577-3265; Fax: +1-570-577-1739.

External Editor: Nicolay Tsarevsky

Received: 16 September 2014; in revised form: 7 October 2014 / Accepted: 20 October 2014 / Published: 24 October 2014

\begin{abstract}
Coupling reactions were performed to gauge the effect of the inclusion of a radical trap on the success of coupling reactions of monohalogenated polystyrene (PSX) chains in atom transfer radical coupling (ATRC) type reactions. The effect of both the specific radical trap chosen and the structure of the polymer chain end were evaluated by the extent of dimerization observed in a series of analogous coupling reactions. The commonly used radical trap 2-methyl-2-nitrosopropane (MNP) showed the highest amounts of dimerization for $\operatorname{PS} X(X=\mathrm{Br}, \mathrm{Cl})$ compared to coupling reactions performed in its absence or with a different radical trap. A dinitroxide coupling agent was also studied with the extent of coupling nearly matching the effectiveness of MNP in RTA (Radical trap-assisted)-ATRC reactions, while $N$-nitroso and electron rich nitroso coupling agents were the least effective. (2,2,6,6-Tetramethyl-piperin-L-yl)oxyl-capped PS (PS-TEMPO), prepared by NMP, was subjected to a coupling sequence conceptually similar to RTA-ATRC, but dimerization was not observed regardless of the choice of radical trap. Kinetic experiments were performed to observe rate changes on the coupling reaction of $\mathrm{PSBr}$ as a result of the inclusion of MNP, with substantial rate enhancements found in the RTA-ATRC coupling sequence compared to traditional ATRC.
\end{abstract}


Keywords: atom transfer radical polymerization; polystyrene; kinetics; radical trap

\section{Introduction}

Radical trap-assisted atom transfer radical coupling (RTA-ATRC) is simply ATRC performed with the inclusion of a radical trapping agent, altering both the mechanistic pathway and the kinetics of the coupling reaction [1-3]. In traditional ATRC (Scheme 1, top), polymer radicals are formed in the absence of monomer, forcing a radical-radical termination reaction that is second order with respect to chain end radical concentration [4-6]. Furthermore, the success of the ATRC coupling reaction relies on the termination pathway being almost exclusively head-to-head coupling, meaning that bulky chain ends such as those on poly(methyl methacrylate) (PMMA) radicals are not compatible [7]. A further restriction is apparent by looking at the kinetic order of the coupling reaction: chain end radicals must be present in concentrations conducive to a bimolecular reaction [8,9]. This means that some halogenated polymer chains, such as poly(methyl acrylate) (PMA) whose ends are secondary radicals at the $\alpha$-ester position, simply do not have $K_{\text {ATRP }}$ values sufficiently high to undergo bimolecular coupling to an appreciable extent [9]. In the RTA-ATRC sequence, the coupling occurs in a step-wise manner with the reaction between the polymer radical and radical trap $\left(k_{1}\right)$ being the rate-limiting step [3].

Scheme 1. Mechanistic comparison and rate comparison of ATRC and RTA-ATRC.

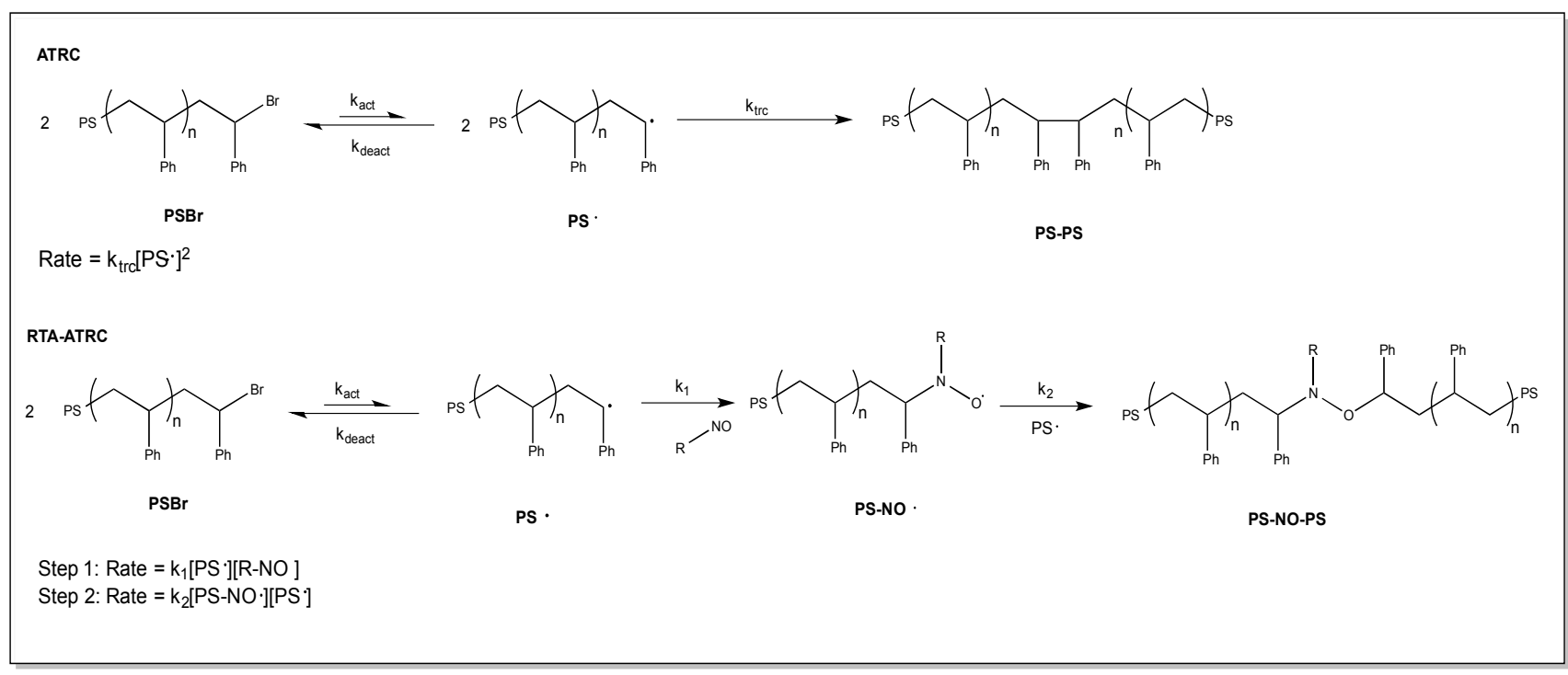

In either ATRC or RTA-ATRC reactions, a major benefit is that polymers formed by atom transfer radical polymerization (ATRP) [10-14] can be directly employed in these coupling reactions without synthetic manipulation of the chain ends. Cyclic polymers can be prepared directly from dibrominated precursors, prepared by ATRP, in both ATRC [15] or RTA-ATRC [16,17] reactions. We have shown, as well, that RTA-ATRC can be successful in instances where ATRC fails. For instance, PMMABr can be dimerized by RTA-ATRC using nitrosobenzene (NBz), due to disproportionation being the favored bimolecular termination pathway [18-21]. Selective coupling is also possible using RTA-ATRC by activating halogenated polymers with different $K_{\text {ATRP }}$ values, preferentially trapping 
the more stable polymer radical as a nitroxide-capped polymer before the other chain is activated and participates in the coupling reaction, ultimately creating diblock copolymers [1].

Despite the success of RTA-ATRC in recent years, a more thorough screening of the relative effectiveness of a series of radical traps in analogous RTA-ATRC reactions has not been done. Additionally presented in this study is the effect of the capping group of the chain end $(\mathrm{Br}, \mathrm{Cl}$, or TEMPO) on the extent of coupling in a series of RTA-ATRC reactions. Lastly, a direct rate comparison between otherwise identical coupling reactions, differing only by the presence or absence of a radical trap, is presented. To simplify the study, PS was used in all cases due to its ease of preparation by ATRP and demonstrated predictability in both ATRC and RTA-ATRC reactions. The ability to employ a greater variety of polymers in coupling reactions, especially those prepared by different methods and as a consequence possessing different end groups, may allow for the synthesis of $\mathrm{AB}$ and $\mathrm{BAB}$-type block copolymers.

\section{Experimental Section}

\subsection{Materials}

Copper(I) bromide (CuBr, 98\%, Aldrich), copper(II) bromide $\left(\mathrm{CuBr}_{2}, 99 \%\right.$, Aldrich, St. Louis, $\mathrm{MO}$, USA), (1-bromoethyl)benzene (1-BEB, 97\%, Aldrich), nano-sized copper ( $\mathrm{Cu}^{0}, 99.8 \%$, Aldrich), and $N, N, N^{\prime}, N^{\prime \prime}, N^{\prime \prime \prime}$-pentamethyldiethylenetriamine (PMDETA, 99\%, Aldrich) were used as received. Tetrahydrofuran (THF) was collected from an Innovative Technology (Oldham, UK) PureSolv solvent purification system. Styrene (99\%, Aldrich) was run through an alumina purification column to remove inhibitor prior to use. Chloroform-d (Aldrich, 99.8\% D, 0.03\% v/v\% TMS) was used as received for NMR (nuclear magnetic resonance) studies. 2-Methyl-2-nitrosopropane dimer (MNP, Aldrich) and alumina (Aldrich) were all used as received. Benzoyl peroxide (BPO, Aldrich, 98\%) and (2,2,6,6-Tetramethyl-piperin-L-yl)oxyl (TEMPO, Aldrich, 98\%) were used as received. The radical traps $N$-tert-Butyl- $\alpha$-phenylnitrone (PBN, Aldrich, 98\%), nitrosobenzene (NBz, Aldrich, 98\%), N,N-dimethyl-4nitrosoaniline (DMNA, Aldrich, 97\%), and $N$-nitrosodiphenylamine (NDPA, Aldrich, 97\%) were used as received. 4,4'-methylebis(phenyl isocyanate) (Aldrich, 98\%), 4-hydroxy-TEMPO (HO-TEMPO, Aldrich, 97\%), and Titanium IV $t$-butoxide (Aldrich, 97\%) were all used as received.

\subsection{PSBr Synthesis}

1-BEB (47.77 $\mu \mathrm{L}, 0.35 \mathrm{mmol}), \mathrm{CuBr}(50.23 \mathrm{mg}, 0.35 \mathrm{mmol})$, styrene (2.0 mL, $17.5 \mathrm{mmol}), 2.0 \mathrm{~mL}$ THF and a dried magnetic stir bar were added to an oven dried two-neck round-bottom flask. The flask was placed on a Schlenk line and subjected to three freeze-pump-thaw cycles. It was then placed in an oil bath at $80{ }^{\circ} \mathrm{C}$. PMDETA $(72.95 \mu \mathrm{L}, 0.35 \mathrm{mmol})$ was added to the flask through a syringe. The reaction stirred at constant temperature for $5 \mathrm{~h}$. The reaction was terminated by placing the flask in an ice bath and opening it up to atmospheric pressure. A small sample was removed from the reaction to perform ${ }^{1} \mathrm{H}$ NMR and GPC (Gel permeation chromatography) analysis. The copper was filtered using a $0.45 \mu \mathrm{m}$ syringe filter and the solution was precipitated out in $100 \mathrm{~mL}$ cold $\mathrm{MeOH}$. PSBr: Number average molecular weight $\left(M_{\mathrm{n}}\right)=3750$, weight average molecular weight $\left(M_{\mathrm{p}}\right)=4000$, dispersity index $Ð=1.09$. 


\subsection{PSCl Synthesis}

A similar reaction as described above was carried out where 1-BEB (47.77 $\mu \mathrm{L}, 0.35 \mathrm{mmol}), \mathrm{CuCl}$ (34.65 mg, $0.35 \mathrm{mmol})$, styrene $(2.0 \mathrm{~mL}, 17.5 \mathrm{mmol}), 2.0 \mathrm{~mL}$ THF and a dried magnetic stir bar were added to an oven dried two-neck round-bottom flask. The flask was placed on a Schlenk line and subjected to three freeze-pump-thaw cycles which was then placed in an oil bath at $80{ }^{\circ} \mathrm{C}$. PMDETA $(72.95 \mu \mathrm{L}, 0.35 \mathrm{mmol})$ was added to the flask through a syringe. The reaction stirred at constant temperature for $5 \mathrm{~h}$. The reaction was terminated by placing the flask in an ice bath and opening it up to atmospheric pressure. A small sample was removed from the reaction to perform ${ }^{1} \mathrm{H}$ NMR and GPC analysis. The copper was filtered using a $0.45 \mu \mathrm{m}$ syringe filter and the solution was precipitated out in $100 \mathrm{~mL}$ cold $\mathrm{MeOH}$. PSCl: $M_{\mathrm{n}}=6700, M_{\mathrm{p}}=9400, Ð=1.35$.

\subsection{PS-TEMPO Synthesis}

BPO (63.5 mg, $0.26 \mathrm{mmol})$, TEMPO (40.97 mg, $0.26 \mathrm{mmol})$, styrene (3.0 mL, $26.22 \mathrm{mmol}$ ) and a dried magnetic stir bar were added to an oven dried two-neck round-bottom flask. The flask was placed on a Schlenk line and subjected to three freeze-pump-thaw cycles which was then placed in an oil bath at $125{ }^{\circ} \mathrm{C}$. PMDETA $(72.95 \mu \mathrm{L}, 0.35 \mathrm{mmol})$ was added to the flask through a syringe. The reaction stirred at constant temperature for $48 \mathrm{~h}$. The reaction was terminated by placing the flask in an ice bath and opening it up to atmospheric pressure. A small sample was removed from the reaction to perform GPC analysis. The solution was precipitated out in $100 \mathrm{~mL}$ cold $\mathrm{MeOH}$. PS-TEMPO: $M_{\mathrm{n}}=7700, M_{\mathrm{p}}=9000, Ð=1.20$.

\subsection{Coupling of PSBr by RTA-ATRC}

To an oven dried two-neck round-bottom flask was added $\mathrm{PSBr}$ precursor ( $250 \mathrm{mg}, 0.025 \mathrm{mmol}), \mathrm{Cu}^{0}$ (4.76 mg, $0.075 \mathrm{mmol}), \mathrm{CuBr}(10.76 \mathrm{mg}, 0.075 \mathrm{mmol})$, 2-methyl-2-nitrosopropane dimer (2.178 mg, $0.0125 \mathrm{mmol}$ ), and $2.0 \mathrm{~mL}$ THF. The flask was then placed on a Schlenk line and subjected to freeze-pump-thaw for three cycles. The flask was then placed in an oil bath at $55^{\circ} \mathrm{C}$. PMDETA $(31.27 \mu \mathrm{L}$, $0.075 \mathrm{mmol}$ ) was added by a syringe and the reaction stirred for $3 \mathrm{~h}$. The reaction was terminated by placing the flask in an ice bath and opening it up to atmospheric pressure. A small sample was removed for GPC analysis. PS-NO-PS: $M_{\mathrm{n}}=6850, M_{\mathrm{p}}=8700, Ð=1.16$.

\subsection{Coupling of PSCl by RTA-ATRC}

A similar reaction to the one described above was carried out using PSCl precursor (100 $\mathrm{mg}$, $0.015 \mathrm{mmol}), \mathrm{Cu}^{0}$ (2.86 mg, $\left.0.045 \mathrm{mmol}\right), \mathrm{CuCl}$ (4.46 mg, $\left.0.045 \mathrm{mmol}\right), 2$-methyl-2-nitrosopropane dimer $(0.784 \mathrm{mg}, 0.009 \mathrm{mmol})$, and $2.0 \mathrm{~mL}$ THF added into an oven dried two-neck round bottom flask. The flask was then placed on a Schlenk line and subjected to freeze-pump-thaw for three cycles. The flask was then placed in an oil bath at $55{ }^{\circ} \mathrm{C}$. PMDETA $(18.76 \mu \mathrm{L}, 0.09 \mathrm{mmol})$ was added by a syringe and the reaction stirred for $3 \mathrm{~h}$. The reaction was terminated by placing the flask in an ice bath and opening it up to atmospheric pressure. PS-NO-PS: $M_{\mathrm{n}}=9100, M_{\mathrm{p}}=14,450, Ð=1.45$. 


\subsection{Coupling of PS-TEMPO by RTA-ATRC}

To an oven dried two-neck round-bottom flask was added PS-TEMPO precursor (250 mg, $0.032 \mathrm{mmol})$, 2-methyl-2-nitrosopropane dimer $(13.9 \mathrm{mg}, 0.08 \mathrm{mmol})$, and $2.0 \mathrm{~mL}$ toluene. The flask was then placed on a Schlenk line and subjected to freeze-pump-thaw for three cycles. The flask was then placed in an oil bath at $135{ }^{\circ} \mathrm{C}$. The reaction stirred for $24 \mathrm{~h}$ and then was terminated by placing the flask in an ice bath and opening it up to atmospheric pressure. A small sample was removed for GPC analysis. Identical reactions were carried out with various radical traps. $\underline{M}_{\mathrm{n}}=8600, M_{\mathrm{p}}=8850$, $Ð=1.25$.

\subsection{Synthesis of 4,4'-Diphenylmethanedicarbamic Acid Di(1-oxy-2,2,6,6-tetramethylpiperidin-4-yl) Ester (DNX, Scheme 2)}

The procedure was modified from a previously reported synthesis of 1,6-hexanedicarbamic acid di(1-oxy-2,2,6,6-tetramethylpiperidin-4-yl) ester [22]. To a flame dried two-neck $50 \mathrm{~mL}$ round bottom flask was added 4,4'-methylebis(phenyl isocyanate) (1.405 g, $0.0056 \mathrm{mmol}$ ), HO-TEMPO (2.130 g, $0.0123 \mathrm{mmol}$ ), $5.0 \mathrm{~mL}$ chloroform, and a dried magnetic stir bar. The flask was then sealed with a Schlenk valve, rubber septum with a copper wire and placed on a Schlenk line and subjected to three freeze-pump-thaw cycles before being placed over a stir plate. To the reaction was added $50 \mu \mathrm{L}$ Titanium IV $t$-butoxide to initiate the reaction and was allowed to stir for $48 \mathrm{~h}$. The reaction was terminated by opening the flask to atmospheric pressure. The solution was diluted with $\sim 30 \mathrm{~mL}$ cold methanol, then stirred into $\sim 90 \mathrm{~mL}$ water, and left in the freezer overnight. The solution was then decanted and this liquid was then placed in the vacuum oven with continuous vacuum use for $\sim 2 \mathrm{~h}$ to afford an orange solid. A small sample was used for ${ }^{1} \mathrm{H}$ NMR analysis.

\subsection{Characterization}

Polymers were analyzed on a Tosoh EcoSEC GPC system (Tosoh Biosciences LLC, Tessenderlo, Belgium) connected to a PC running EcoSEC data analysis software. The system was temperature controlled at $40{ }^{\circ} \mathrm{C}$, and was equipped with a UV detector, a dual flow refractive index (RI) detector and two TSK gel super Multipore H-ZM columns. A five-point calibration was obtained with polystyrene standards (Tosoh, Minato, Japan, $M_{\mathrm{p}}$ range: $2.6 \times 10^{2}$ to $7.06 \times 10^{5} \mathrm{~g} / \mathrm{mol}$ ) and was used to obtain molecular weight characteristics and dispersity index $(\nexists)$ values of all polymers. Percent monomer conversion values for ATRP reactions were determined by ${ }^{1} \mathrm{H}$ NMR on the raw mixture in $\mathrm{CDCl}_{3}$. ${ }^{1} \mathrm{H}$ NMR measurements were taken on a Varian (Palo Alto, CA, USA) $400 \mathrm{MHz}$ FT (Fourier Transform)-NMR at room temperature.

\section{Results and Discussion}

\subsection{Role of the Radical Trap in RTA-ATRC Reactions of PSBr Chains}

The specific radical trap can affect both $k_{1}$ and $k_{2}$ in the RTA-ATRC mechanism (Scheme 1, bottom), either directly by its role as a reactant (Step 1) or by its transformation into a nitroxide that participates in Step 2. To illustrate this point using PMMA radicals, the bulky radical trap MNP results 
in a sterically hindered nitroxide-capped PMMA unable to couple with another PMMA radical [7]. Substituting MNP with NBz allows for near quantitative dimerization of PMMA, highlighting just how large of a role the radical trap can play. The initial goal of this work is to gauge the extent of dimerization as a function of the radical trap in coupling reactions of PSBr. Conditions were chosen so that a traditional ATRC reaction was able to achieve high amounts of dimerization with various $\mathrm{PSBr}$ precursors (Table 1, trials 1,4), as observed by GPC, and serve as baseline reference points; reactions with the inclusion of a radical trap were then compared to these results.

Table 1. Coupling of PSBr (polystyrene Br) chains in RTA-ATRC (Radical trap-assisted atom transfer radical coupling) reactions using various nitroso coupling agents.

\begin{tabular}{|c|c|c|c|c|c|c|c|c|}
\hline \multicolumn{4}{|c|}{ PSBr Precursor $^{\text {a }}$} & \multicolumn{5}{|c|}{ RTA-ATRC and ATRC Products ${ }^{b}$} \\
\hline Trial & $M_{\mathbf{n}} \mathbf{c}$ & $M_{\mathbf{p}}{ }^{\mathrm{e}}$ & $\boldsymbol{D}^{\mathrm{f}}$ & $\begin{array}{c}\text { Coupling } \\
\text { Trap }^{d} \\
\end{array}$ & $M_{\mathrm{n}}{ }^{c}$ & $M_{\mathbf{p}}{ }^{\mathbf{e}}$ & $\boldsymbol{D}^{\mathrm{f}}$ & $\begin{array}{c}{[\mathrm{PSBr}]:[\mathrm{CuBr}]:\left[\mathrm{Cu}^{0}\right]:} \\
{[\text { PMDETA]:[Radical Trap] }}\end{array}$ \\
\hline 1 & 3,750 & 4,000 & 1.09 & - & 6,600 & 8,600 & 1.19 & $1: 5: 5: 10:-$ \\
\hline 2 & 3,750 & 4,000 & 1.09 & DNX & 7,200 & 10,750 & 1.24 & $1: 5: 5: 10: 0.6$ \\
\hline 3 & 3,750 & 4,000 & 1.09 & MNP & 6,850 & 8,700 & 1.16 & $1: 5: 5: 10: 0.6$ \\
\hline 4 & 7,650 & 8,000 & 1.15 & ATRC & 13,200 & 17,600 & 1.35 & $1: 3: 3: 6:-$ \\
\hline 5 & 7,650 & 8,000 & 1.15 & DNX & 12,100 & 18,700 & 1.33 & $1: 3: 3: 6: 0.6$ \\
\hline 6 & 7,650 & 8,000 & 1.15 & MNP & 13,350 & 16,200 & 1.25 & $1: 3: 3: 6: 0.6$ \\
\hline 7 & 6,450 & 6,800 & 1.08 & DMNA & 7,450 & 6,830 & 1.18 & $1: 3: 3: 6: 0.6$ \\
\hline 8 & 6,450 & 6,800 & 1.08 & NDPA & 9,050 & 13,700 & 1.21 & $1: 3: 3: 6: 0.6$ \\
\hline 9 & 6,450 & 6,800 & 1.08 & $\mathrm{NBz}$ & 10,800 & 13,700 & 1.16 & $1: 3: 3: 6: 0.6$ \\
\hline \multicolumn{9}{|c|}{$\begin{array}{l}\text { a PSBr was prepared by ATRP using the ratios }[\mathrm{St}]:[1-\mathrm{BEB}]:[\mathrm{CuBr}]:[\mathrm{PMDETA}]=50: 1: 1: 1 ; T=80{ }^{\circ} \mathrm{C} ; 5 \mathrm{~h} ;{ }^{\mathrm{b}} \mathrm{ATRC} \text { or } \\
\text { RTA-ATRC product after } 3 \mathrm{~h} \text { of reaction time at } 55{ }^{\circ} \mathrm{C} ;{ }^{\mathrm{c}} \text { Number-average weights obtained by GPC calibrated with } \\
\text { linear polystyrene standards, expressed in } \mathrm{Da} ;{ }^{\mathrm{d}} \text { See Scheme } 2 \text { for structures; }{ }^{\mathrm{e}} \text { Peak molecular weights obtained by GPC } \\
\text { calibrated with linear polystyrene standards, expressed in Da; }{ }^{\mathrm{f}} \text { Dispersity index }(\nexists) \text { values obtained by GPC calibrated } \\
\text { with linear polystyrene standards. }\end{array}$} \\
\hline
\end{tabular}

The structures of the radical traps used in the RTA-ATRC reactions of PSBr are shown in Scheme 2. Figure 1a shows the GPC trace of the PSBr precursor, and the coupled product resulting from a traditional ATRC (Table 1, trial 1) and that of the well-studied MNP as the radical trap (making it an RTA-ATRC reaction; trial 3). High amounts of dimerization were observed in both coupling reactions, as expected with $\mathrm{PSBr}$ as the precursor, which generates a secondary benzylic radical upon activation. Coupling was observed by a shift in the peak molecular weight $\left(M_{\mathrm{p}}\right)$ of the RTA-ATRC product compared to the $\mathrm{PSBr}$ precursor from which it was derived. As can be seen in Figure 1a, substantial dimerization also occurred using DNX as the radical trap (Table 1, trial 2), with the coupled product shifting to higher $M_{\mathrm{p}}$ values compared to the ATRC or RTA-ATRC using MNP. This can be explained by the larger, more rigid DNX creating a larger spacer between the PS chains in the dimer.

Several more radical traps were studied in the RTA-ATRC reaction of PSBr, with results listed in Table 1 and the structures of the radical traps given in Scheme 2. As can be visualized in Figure 1b, the extent of dimerization was dependent on the specific radical trap chosen, with only NBz leading to high amounts of dimerization approaching that of MNP (Table 1, trial 9). Poor coupling was seen with DMNA (Figure 1b; Table 1, trial 7), probably due to direct conjugation between the nitroso with the amine group resulting in stabilization and lowered reactivity of the nitroso functionality. The $N$-nitroso 
trap NDPA lead to more dimerization than DMNA in an analogous RTA-ATRC reaction, but was still less effective than traditional ATRC (Figure 1b, Table 1, trial 8). NBz, which is especially effective as a radical trap in the dimerization of PMMA chains, also was effective in coupling PSBr (Figure 1b, Table 1, trial 9), giving rise to PS dimers to an extent nearly that of MNP as the radical trap. Any lack of dimerization can be attributed to the specific trapping agent and other conditions of the coupling reaction, as even PSBr prepared by ATRP under identical conditions is capable of undergoing near quantitative dimerization in ATRC reactions [23].

Scheme 2. Structures of radical traps used in Tables 1-4.

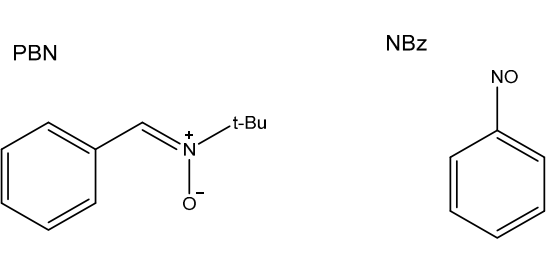<smiles>CN(C)c1ccc([N+](=O)[O-])cc1</smiles>

NDPA<smiles>CC1(C)CC(OC(=O)Nc2ccc(Cc3ccc(NC(=O)OC4CC(C)(C)N(O)C(C)(C)C4)cc3)cc2)CC(C)(C)N1O</smiles><smiles>O=[N+](c1ccccc1)c1ccccc1</smiles>

$$
\begin{aligned}
& \mathrm{PBN}=\mathrm{N} \text {-tert-Butyl-a-phenylnitrone } \\
& \mathrm{NBz}=\text { Nitrosobenzene } \\
& \mathrm{MNP}=\text { =-Methyl-2-nitrosopropane } \\
& \mathrm{DMNA}=\mathrm{N}, \mathrm{N}-\text {-Dimethyl-4-nitrosoaniline } \\
& \mathrm{NDPA}=\mathrm{N}-\text { Nitrosodiphenylamine } \\
& \text { DNX }=\text { Dinitroxide }
\end{aligned}
$$

Figure 1. Refractive index-gel permeation chromatography (RI-GPC) traces of PSBr in analogous RTA-ATRC reactions with different nitroso coupling agents. See Table 1 for specifics of molecular weight data and characteristics.

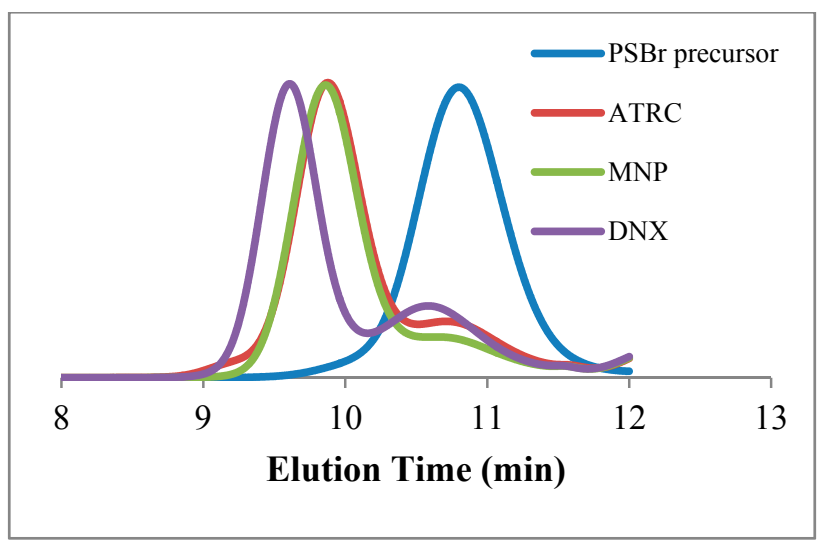

(a)

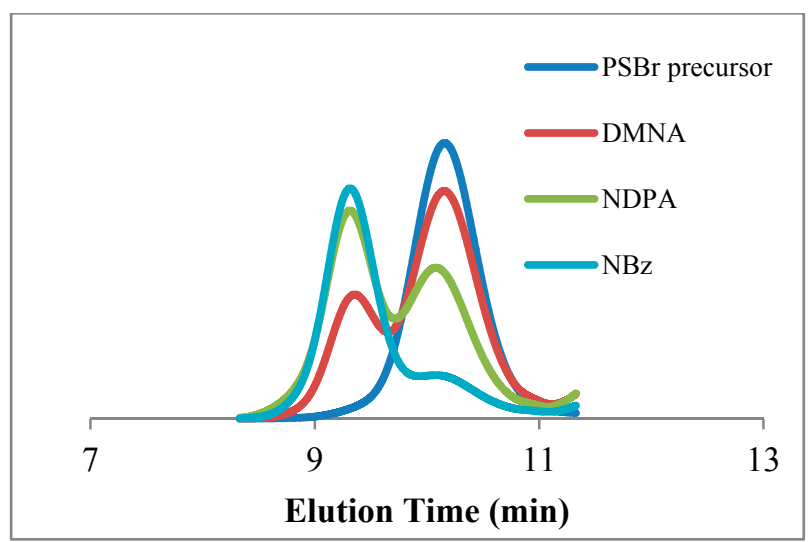

(b) 


\subsection{Coupling PSCl Chains Using ATRC and RTA-ATRC}

While PSBr has proven to be suitable for either traditional ATRC or RTA-ATRC reactions with certain radical traps, $\mathrm{PSCl}$ has proven less cooperative at least in ATRC reactions [23]. The increased $\mathrm{C}-\mathrm{Cl}$ bond strength, compared to the $\mathrm{C}-\mathrm{Br}$ bond, makes $\mathrm{PSCl}$ less active in ATRC reactions due to the success of coupling relying on PS radicals undergoing a bimolecular coupling reaction (Scheme 1, top). In this study, PSCl simply replaced the PSBr as precursors in a series of coupling reactions. Therefore, the "baseline" ATRC reactions of the PSCl did not lead to appreciable coupling (Table 2, trial 1), and the inclusion of various radical traps in this case was to explore the possibility of successfully coupling PSCl chains under lenient RTA-ATRC-type conditions matching those of PSBr.

As seen in Table 2, trial 1, only a small increase in molecular weight was observed in coupling reactions of $\mathrm{PSCl}$ in the absence of a radical trap (traditional ATRC) consistent with only a small portion of chains reacting intermolecularly. The inclusion of DNX or MNP, which were especially effective traps in coupling reactions of $\mathrm{PSBr}$, showed a modest increase in molecular weight after the RTA-ATRC reaction compared to the PSCl precursor, yet did not lead to appreciable dimerization (Table 2, trials 2,3,6 and Figure 2). RTA-ATRC attempts using newly studied radical traps (Table 2, trials 4,5) mirrored the poor coupling results when compared to ATRC or RTA-ATRC with MNP or DNX, but with overall much poorer coupling than analogous reactions using PSBr. The low concentration of the radical trap (0.6 eq compared to PSCl chain ends) rules out that chain ends are simply being capped by the radical trap, leading to persistent nitroxide-capped PS chains unable to participate further in the RTA-ATRC sequence (due to a lack of PS radicals as partners). The poor coupling results simply reflect the lowered concentrations of PS radicals available to begin the RTA-ATRC sequence when performed at these mild conditions $\left(55^{\circ} \mathrm{C}, 3\right.$-fold excess catalyst and reducing agent). These results indicate that even the inclusion of a radical trap is not enough to overcome the decreased $K_{\mathrm{ATRP}}$ value of the PSCl compared to the PSBr under our reaction conditions.

Table 2. Coupling of PSCl chains in ATRC and RTA-ATRC reactions using various nitroso coupling agents.

\begin{tabular}{|c|c|c|c|c|c|c|c|c|}
\hline \multicolumn{4}{|c|}{ PSCl Precursor ${ }^{a}$} & \multicolumn{5}{|c|}{ RTA-ATRC and ATRC Products ${ }^{b}$} \\
\hline Trial & $M_{\mathrm{n}}{ }^{\mathrm{c}}$ & $M_{\mathrm{p}}^{\mathrm{e}}$ & $\boldsymbol{D}^{\mathrm{f}}$ & $\begin{array}{c}\text { Coupling } \\
\text { Trap }^{\mathrm{d}}\end{array}$ & $M_{\mathrm{n}}{ }^{\mathrm{c}}$ & $M_{p}{ }^{e}$ & $\boldsymbol{\theta}^{\mathrm{f}}$ & $\begin{array}{c}{[\mathrm{PSCl}]:[\mathrm{CuCl}]:\left[\mathrm{Cu}^{0}\right]:} \\
{[\text { PMDETA]:[Radical Trap] }}\end{array}$ \\
\hline 1 & 6,700 & 9,400 & 1.35 & - & 7,400 & 10,400 & 1.41 & 1:3:3:6:- \\
\hline 2 & 6,700 & 9,400 & 1.35 & DNX & 8,000 & 11,100 & 1.44 & $1: 3: 3: 6: 0.6$ \\
\hline 3 & 6,700 & 9,400 & 1.35 & MNP & 9,100 & 14,450 & 1.45 & $1: 3: 3: 6: 0.6$ \\
\hline 4 & 6,450 & 8,050 & 1.24 & DMNA & 5,200 & 8,100 & 1.45 & $1: 3: 3: 6: 0.6$ \\
\hline 5 & 6,450 & 8,050 & 1.24 & NDPA & 5,750 & 8,200 & 1.41 & $1: 3: 3: 6: 0.6$ \\
\hline 6 & 6,450 & 8,050 & 1.24 & MNP & 6,650 & 13,450 & 1.66 & $1: 3: 3: 6: 0.6$ \\
\hline 7 & 6,450 & 8,050 & 1.24 & $\mathrm{NBz}$ & 7,150 & 13,800 & 1.72 & $1: 3: 3: 6: 0.6$ \\
\hline
\end{tabular}

a $\mathrm{PSCl}$ was prepared by ATRP at $80{ }^{\circ} \mathrm{C}$ for $5 \mathrm{~h}$ using the ratios [St]:[1-BEB]:[CuCl]:[PMDETA] = 50:1:1:1;

${ }^{\mathrm{b}}$ ATRC or RTA-ATRC product after $3 \mathrm{~h}$ of reaction time at $55{ }^{\circ} \mathrm{C}$; ${ }^{\mathrm{c}}$ Number-average weights obtained by GPC calibrated with linear PS standards, expressed in Da; ${ }^{\mathrm{d}}$ See Scheme 2 for structures; ${ }^{\mathrm{e}}$ Peak molecular weights obtained by GPC calibrated with linear PS standards, expressed in Da; ${ }^{\mathrm{f}}$ Dispersity index $(\nexists)$ values obtained by GPC calibrated with linear PS standards. 
Figure 2. RI-GPC traces of PSCl in RTA-ATRC reactions with different coupling agents.

See Table 2 for specifics of molecular weight data and characteristics.

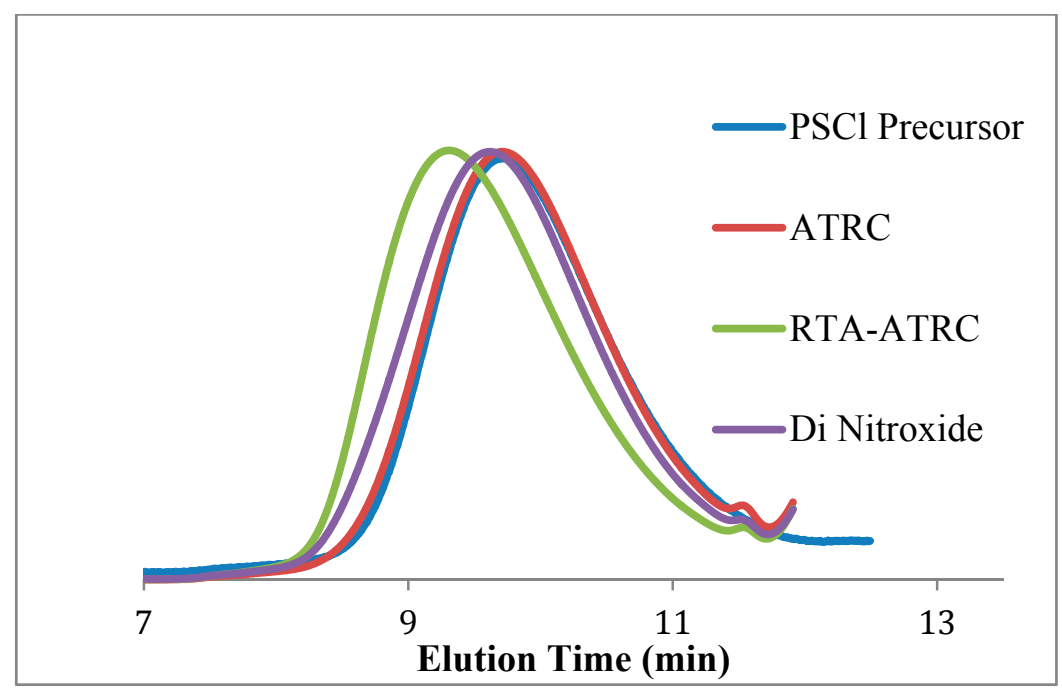

\subsection{Coupling PS-TEMPO Chains Using RTA-ATRC-Type Reactions}

The possibility of employing PS-TEMPO, prepared by nitroxide mediated polymerization (NMP), in a sequence conceptually similar to ATRC and RTA-ATRC was explored. In this case, the mechanistic steps differ from those in the above experiments and rely not on an atom transfer reaction to create active polymer radicals, but instead homolytic cleavage of the chain end alkoxyamine (Scheme 3) [24-26]. In this case, the concentration of the radical trap was increased to five times that of the polymer end group in order to have a better chance at participating in a reaction with the active polymer. As can be seen from Scheme 3, the rate constant for deactivation back to the TEMPO-capped polymer $\left(k_{\text {deact }}\right)$ will approximate that of $k_{2}$ in the RTA-ATRC sequence (also labeled $k_{2}$ in Scheme 3), and will be substantially higher than $k_{\text {c }}$. Additionally, the temperature of the coupling reaction was increased to $135{ }^{\circ} \mathrm{C}$, to match conditions typical of an NMP reaction [27] and generate PS radicals.

Scheme 3. Coupling in PS-TEMPO chains using a radical trap. Although not an RTA-ATRC reaction, it is conceptually similar to the pathway in Scheme 1, bottom.

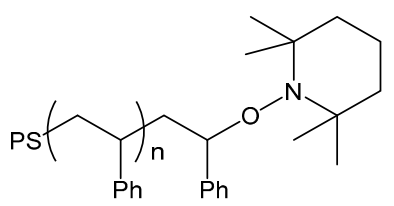

PS-TEMPO

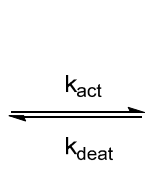<smiles>CC(C)(P)CCCC(Pc1ccccc1)C(CCCc1ccccc1)CC(C)(C)c1ccccc1</smiles><smiles></smiles>
PS-TEMPO

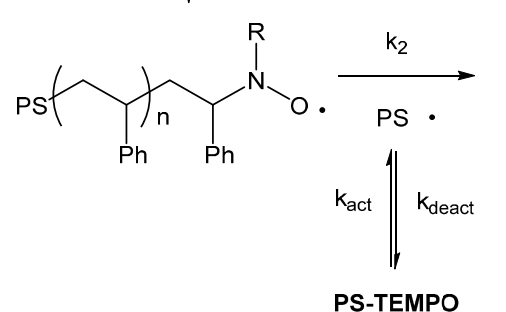<smiles>CC1(C)CCCC(C)(C)N1O</smiles><smiles>[R]N(OC(CC(C)CC(C)(C)[Pb])c1ccccc1)C(CC(C)CC(C)(C)P)c1ccccc1</smiles>
PS-NO-PS 
Experimentally simpler to carry out, PS-TEMPO was prepared by NMP and, after purification and isolation, heated to induce $\mathrm{C}-\mathrm{O}$ cleavage in the presence of a variety of radical traps as listed in Table 3 . GPC traces of the PS-TEMPO precursor and the results of the attempted coupling reactions can be visualized in Figure 3, with only minor increases in molecular weights observed in any case. Despite the relative lack of dimerization, it is worth noting that the trend of coupling extent mirrored that found in the case of PSBr. For example, the inclusion of MNP (Table 3, trial 1) lead to the largest portion of higher molecular shoulder on the coupled product, while coupling attempts using NDPA (trials 4,7) essentially lead to no observable change in the molecular weight compared to the PS-TEMPO precursor as shown in Figure 3. Because of the lack of success of these agents, a nitrone compound that found success in PSBr reactions [28] was attempted (PBN, Scheme 2). Coupling reactions using this nitrone (trials 2,6) lead to a high molecular weight shoulder indicating some intermolecular coupling, but its effectiveness was still less than MNP.

Table 3. Coupling of PS-TEMPO chains in RTA-ATRC-type reactions (Scheme 3) using various nitroso coupling agents.

\begin{tabular}{|c|c|c|c|c|c|c|c|}
\hline \multicolumn{4}{|c|}{ PS-TEMPO Precursor ${ }^{a}$} & \multicolumn{4}{|c|}{ RTA-ATRC Products ${ }^{\text {b }}$} \\
\hline Trial & $M_{\mathrm{n}}{ }^{\mathrm{c}}$ & $M_{p}{ }^{d}$ & $\boldsymbol{D}^{\mathrm{e}}$ & Radical Trap $^{\mathrm{f}}$ & $M_{\mathrm{n}}{ }^{c}$ & $M_{p}{ }^{d}$ & $\boldsymbol{D}^{\mathrm{e}}$ \\
\hline 1 & 7,700 & 9,000 & 1.20 & MNP & 8,600 & 8,850 & 1.28 \\
\hline 2 & 7,700 & 9,000 & 1.20 & PBN & 8,300 & 8,850 & 1.25 \\
\hline 4 & 7,700 & 9,000 & 1.20 & NDPA & 7,800 & 8,750 & 1.21 \\
\hline 5 & 11,800 & 16,000 & 1.34 & MNP & 11,600 & 15,550 & 1.34 \\
\hline 6 & 11,800 & 16,000 & 1.34 & PBN & 11,900 & 16,100 & 1.30 \\
\hline 7 & 11,800 & 16,000 & 1.34 & NDPA & 12,550 & 16,850 & 1.34 \\
\hline
\end{tabular}

a PS-TEMPO was prepared by NMP using the ratios [St]:[BPO]:[TEMPO] $=100: 1: 1 ; T=125{ }^{\circ} \mathrm{C} ; 48 \mathrm{~h}$;

${ }^{\mathrm{b}}$ RTA-ATRC product after $24 \mathrm{~h}$ of reaction time at $135^{\circ} \mathrm{C}$. The RTA-ATRC products were prepared using the ratios [PS-TEMPO]:[Radical Trap] $=1: 5$; $^{\mathrm{c}}$ Number-average weights obtained by GPC calibrated with linear polystyrene standards, expressed in Da; ${ }^{\mathrm{d}}$ Peak molecular weights obtained by GPC calibrated with linear polystyrene standards, expressed in Da; ${ }^{\mathrm{e}}$ Dispersity index $(\nexists)$ values obtained by GPC calibrated with linear polystyrene standards; ${ }^{\mathrm{f}}$ See Scheme 2 for structures.

Figure 3. RI-GPC traces of PS-TEMPO in RTA-ATRC-type coupling reactions (Scheme 3). See Table 3 for specifics of molecular weight data and characteristics.

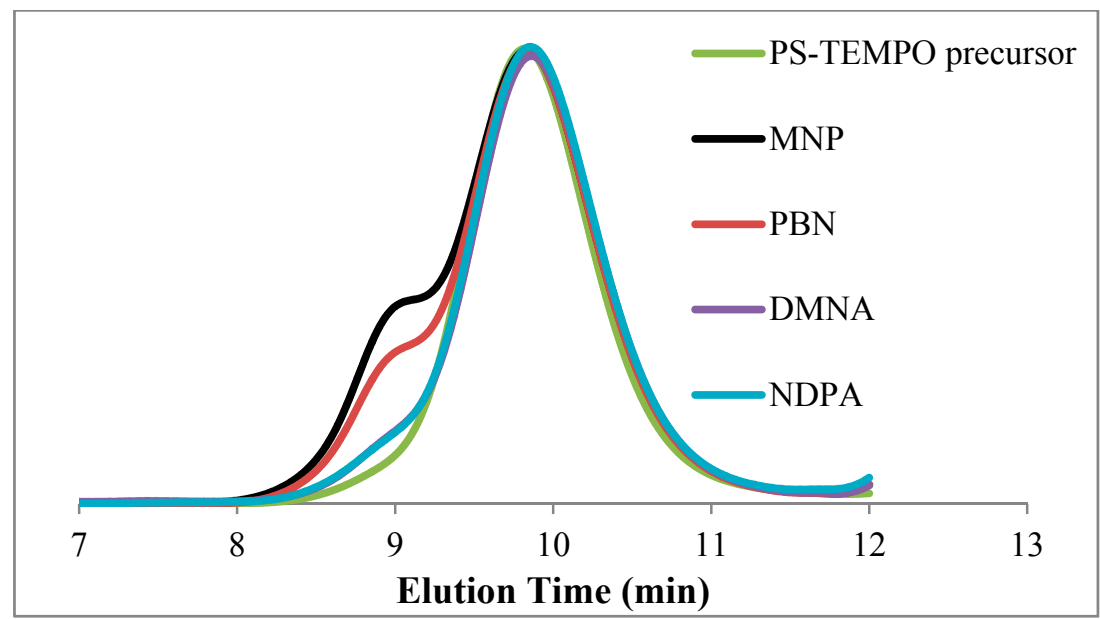




\subsection{Kinetic Comparison between ATRC and RTA-ATRC in Coupling PSBr}

The work above shows that the inclusion of a radical trap in the RTA-ATRC sequence is not enough to overcome poorer leaving groups on the polymer's terminus and, despite altering the coupling sequence and rate equations compared to ATRC, dimerization was largely unsuccessful for both Cl-capped and TEMPO-capped PS chains. Attention was now returned to PSBr as the precursor and the most effective radical trap: MNP. A kinetics study was performed to compare the two coupling reactions, ATRC and RTA-ATRC, where the latter reaction was carried out in the presence of MNP. Again, conditions were mild for an ATRC reaction $\left(55^{\circ} \mathrm{C}, 3\right.$-fold excess catalyst and reducing agent), with only 0.6 eq of MNP added to the RTA-ATRC reaction.

The PSBr precursor polymers were prepared by typical ATRP reactions performed for $5 \mathrm{~h}$ at $80{ }^{\circ} \mathrm{C}$ using the initiator (1-bromoethyl) benzene (1-BEB). The ratios of the reactants were 50:1:1:1 ([St]:[1-BEB]:[CuBr]:[PMDETA]) and the reactions were stopped at low conversions, affording polymers in the molecular weight range of 4000-5000 Da. Once the reaction was complete, a small aliquot was taken for GPC analysis and the remaining polymer was purified and isolated. The polymer was then employed in an ATRC reaction with copper catalyst, elemental copper, ligand, and THF

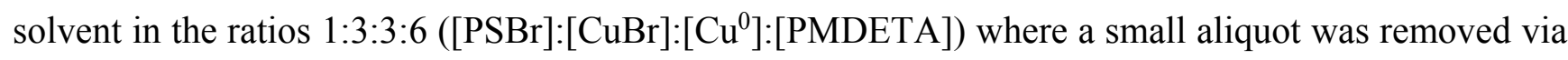
an argon-flushed syringe every $10 \mathrm{~m}$ for GPC analysis of the progression of the reaction. An analogous RTA-ATRC reaction was carried out with the ratios matching the ATRC, but with 0.6 eq of MNP

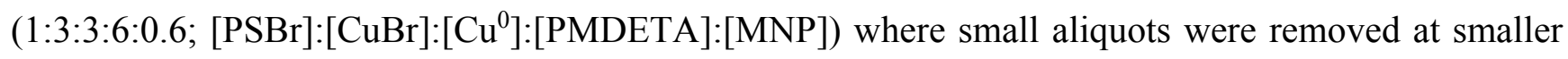
time intervals initially of $2-5 \mathrm{~min}$ for GPC analysis.

The results of the comparison between the ATRC and RTA-ATRC reactions are shown in Table 4. For the ATRC reaction, the $M_{\mathrm{p}}$ of the coupled product had an apparent value essentially double that of the precursor $\left(\mathrm{PSBr}: M_{\mathrm{p}}=4950\right)$ after approximately $25 \mathrm{~m}$ of the reaction had elapsed (Table 4, Sample \#5, ATRC). When an otherwise identical reaction was run but with the addition of the radical trap MNP, this RTA-ATRC reaction resulted in large amounts of coupled product significantly faster. For the dimerized product, the $M_{\mathrm{p}}$ value was approximately double that of the precursor after only $7 \mathrm{~m}$, while taking approximately $25 \mathrm{~m}$ for the ATRC reaction to generate similar results (Table 4, Sample \#3, RTA-ATRC). The presence of coupled product can also be observed in the GPC traces in Figure 4 with a steady shift to higher molecular weights as the reaction proceeds, with $M_{\mathrm{p}}$ values approximately double that of the precursor PSBr.

The results of this kinetics study indicate that the rate-limiting step in RTA-ATRC (Scheme 1, bottom, Step 1) occurs at a faster rate than the bimolecular coupling reaction required for ATRC. Although the rate constant $k_{\text {trc }}$ in the ATRC reaction is expected to be significantly larger than the rate constant of the rate limiting step of RTA-ATRC $\left(k_{1}\right)$, this is more than off-set by the molecularity change of the PS radical going from second order in ATRC to first order in RTA-ATRC. 
Table 4. Kinetic study of coupling reactions of PSBr in ATRC and RTA-ATRC reactions.

\begin{tabular}{|c|c|c|c|c|c|c|c|c|}
\hline \multirow[b]{2}{*}{ Sample \# } & \multicolumn{4}{|c|}{ ATRC Product ${ }^{a}$} & \multicolumn{4}{|c|}{ RTA-ATRC Product ${ }^{b}$} \\
\hline & $\begin{array}{c}\text { Time of Sample } \\
\text { Taken }{ }^{c} \text { (min) }\end{array}$ & $M_{\mathrm{n}}^{\mathrm{d}}$ & $M_{\mathrm{p}}{ }^{\mathrm{e}}$ & $\boldsymbol{D}^{\mathrm{f}}$ & $\begin{array}{c}\text { Time of Sample } \\
\text { Taken c (min) }\end{array}$ & $M_{\mathrm{n}}^{\mathrm{d}}$ & $M_{\mathrm{p}} \mathrm{e}^{-}$ & $\boldsymbol{D}^{\mathrm{f}}$ \\
\hline 1 & 10 & 4,650 & 5,100 & 1.24 & 2 & 4,550 & 5,000 & 1.23 \\
\hline 2 & 20 & 5,100 & 5,150 & 1.31 & 5 & 4,700 & 5,050 & 1.34 \\
\hline 3 & 25 & 5,350 & 9,950 & 1.37 & 7 & 5,000 & 9,650 & 1.34 \\
\hline 4 & 30 & 5,650 & 9,850 & 1.37 & 10 & 5,250 & 9,800 & 1.37 \\
\hline 5 & 40 & 5,950 & 10,050 & 1.41 & 15 & 5,700 & 9,950 & 1.37 \\
\hline 6 & 50 & 6,500 & 10,000 & 1.36 & 20 & 5,850 & 10,000 & 1.39 \\
\hline 7 & 60 & 5,700 & 9,900 & 1.47 & 25 & 6,000 & 10,000 & 1.39 \\
\hline 8 & - & - & - & - & 30 & 5,650 & 10,000 & 1.46 \\
\hline 9 & - & - & - & - & 40 & 5,750 & 9,950 & 1.46 \\
\hline 10 & - & - & - & - & 50 & 5,700 & 10,000 & 1.47 \\
\hline
\end{tabular}

${ }^{a}$ Monobrominated polystyrene (PSBr) was prepared by ATRP using the ratios: [St]:[1-BEB]:[CuBr]:[PMDETA] = 50:1:1:1; $T=80^{\circ} \mathrm{C} ; 5 \mathrm{~h}$. PSBr: $M_{\mathrm{n}}=4400, M_{\mathrm{p}}=4950, Ð=1.13$. Dimerized PS-PS product was prepared by ATRC using the ratios: [PSBr]:[CuBr]:[Cu$\left.{ }^{0}\right]:[\mathrm{PMDETA}]=1: 3: 3: 6 ; T=60{ }^{\circ} \mathrm{C} ; 1 \mathrm{~h} ;{ }^{\mathrm{b}}$ Monobrominated polystyrene (PSBr) was prepared by ATRP using the ratios: $[\mathrm{St}]:[1-\mathrm{BEB}]:[\mathrm{CuBr}]:[\mathrm{PMDETA}]=50: 1: 1: 1 ; T=80^{\circ} \mathrm{C} ; 5 \mathrm{~h}$. PSBr: $M_{\mathrm{n}}=4000, M_{\mathrm{p}}=4600, Ð=1.14$. Dimerized PS-PS product was prepared by RTA-ATRC using the ratios: $[\mathrm{PSBr}]:[\mathrm{CuBr}]:\left[\mathrm{Cu}^{0}\right]:[\mathrm{PMDETA}]:[\mathrm{MNP}]=$ 1:3:3:6:0.6; $T=60{ }^{\circ} \mathrm{C} ; 1 \mathrm{~h} ;{ }^{\mathrm{c}}$ Time elapsed for sample taken from the reaction for GPC analysis; ${ }^{\mathrm{d}}$ Number average molecular weights obtained by GPC calibrated with linear polystyrene standards, expressed in Da; ${ }^{e}$ Peak molecular weights obtained by GPC calibrated with linear polystyrene standards, expressed in Da; ${ }^{\mathrm{f}}$ Dispersity index $(\nexists)$ values obtained by GPC calibrated with linear polystyrene standards.

Figure 4. (a) Overlaid GPC traces of PSBr precursor and the ATRC product showing traces of samples at various time intervals. PSBr: $M_{\mathrm{n}}=4400, M_{\mathrm{p}}=4950, Ð=1.13,5 \mathrm{~h}, 80{ }^{\circ} \mathrm{C}$, with ratios $[\mathrm{St}]:[1-\mathrm{BEB}]:[\mathrm{CuBr}]:[\mathrm{PMDETA}]=50: 1: 1: 1$. ATRC product: $M_{\mathrm{n}}=5700, M_{\mathrm{p}}=9900$, $Ð=1.47$, total volume $=4 \mathrm{~mL}, 60 \mathrm{~min}$, with ratios $[\mathrm{PSBr}]:\left[\mathrm{Cu}^{0}\right]:[\mathrm{CuBr}]:[$ PMDETA $]=1: 3: 3: 6$ (Table 4, Sample \#1-7, ATRC); (b) Overlaid GPC traces of PSBr precursor and the RTA-ATRC product showing traces of samples at various time intervals. PSBr: $M_{\mathrm{n}}=4000$, $M_{\mathrm{p}}=4600, Ð=1.14,5 \mathrm{~h}, 80^{\circ} \mathrm{C}$, with ratios [St]:[1-BEB]:[CuBr]:[PMDETA] $=$ 50:1:1:1. RTA-ATRC product: $M_{\mathrm{n}}=5700, M_{\mathrm{p}}=10,000, Ð=1.47$, total volume $=4 \mathrm{~mL}, 1 \mathrm{~h}$, with ratios [PSBr]:[Cu$\left.{ }^{0}\right]:[\mathrm{CuBr}]:[\mathrm{PMDETA}]:[\mathrm{MNP}]=1: 3: 3: 6: 0.6$ (Table 4, Sample \#1-10), RTA-ATRC).

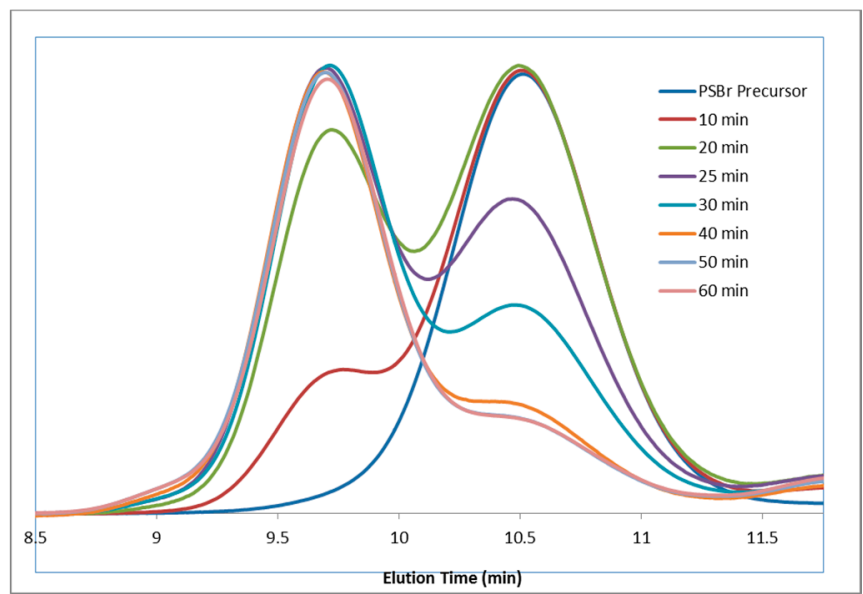

(a)

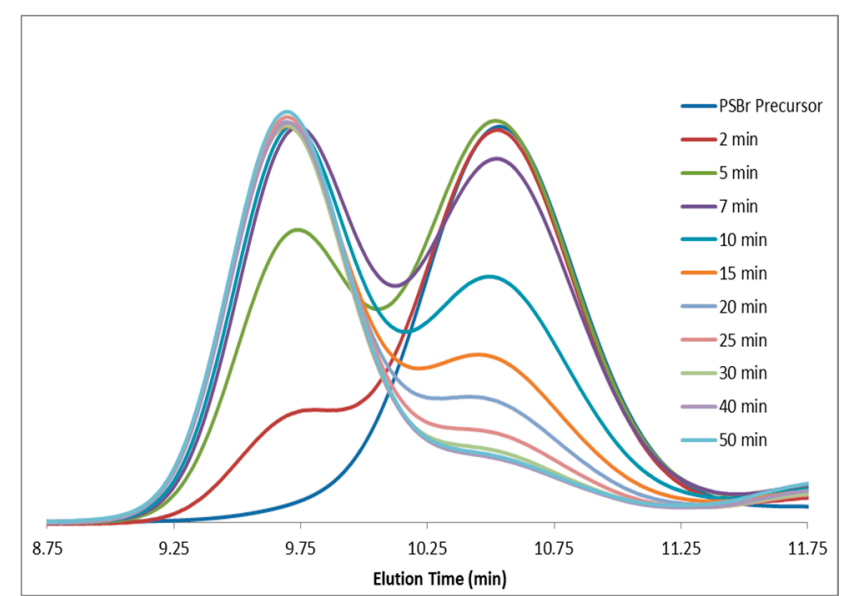

(b) 


\section{Conclusions}

The involvement of the radical trap MNP lead to the highest extent of dimerization of PSBr in RTA-ATRC reactions, and outperformed analogous ATRC reactions. When other radical traps were included in the coupling sequence of PSBr, the improvement compared to traditional ATRC was less pronounced or, in the case of NDPA and DMNA, worsened. The dinitroxide compound DNX was also explored, and lead to high amounts of dimers more than twice the size of the precursor; a consequence of its bulky structure. RTA-ATRC reactions using PSCl instead of PSBr, but holding other reaction parameters the same, were not successful in producing substantial amounts of dimer due to the decreased concentrations of PS radical available. When PS-TEMPO was thermally activated in the presence of various radical traps, only small amounts of intermolecular coupling was observed. Lastly, the inclusion of the nitroso radical trap MNP in ATRC reactions, mechanistically altering it to a stepwise RTA-ATRC coupling sequence, lead to higher extents of dimerization of PSBr chains per unit time compared to traditional ATRC.

\section{Acknowledgments}

This work was supported by NSF (Award \# 1307133), a Beckman Scholar Award, Bucknell's Program for Undergraduate Research, and the Office of Graduate Studies.

\section{Author Contributions}

Eric Tillman conceived of the experiments. Elizabeth Carnicom designed and carried out the kinetics experiments. Yacouba Sidibe and Jessica Abruzzese performed polymerization and coupling experiments. Kenneth Myers synthesized radical traps not commercially available. Eric Tillman and Elizabeth Carnicom wrote the paper.

\section{Conflicts of Interest}

The authors declare no conflict of interest.

\section{References}

1. Butcher, W.E.; Radzinski, S.C.; Tillman, E.S. Selective formation of diblock copolymers using radical trap-assisted atom transfer radical coupling. J. Poly. Sci. A Polym. Chem. 2013, 51, 3619-3626.

2. Carnicom, E.M.; Coyne, W.E.; Myers, K.D.; Tillman, E.S. One pot, two step sequence converting Atom transfer radical polymerization directly to radical trap-assisted atom transfer radical coupling. Polymer 2013, 54, 5560-5567.

3. Zhang, C.; Wang, Q. Degradable multisegmented polymers synthesized by consecutive radical addition-coupling reaction of $\alpha, \omega$-macrobiradicals and nitroso compound. J. Poly. Sci. A Polym. Chem. 2011, 49, 612-618.

4. Sarbu, T.; Lin, K.; Ell, J.; Siegwart, D.; Spanswick, J.; Matyjaszewski, K. Polystyrene with designed molecular weight distribution by atom transfer radical coupling. Macromolecules 2004, $37,3120-3127$. 
5. Atanu, K.; Chatterjee, D.P.; Layek, R.K.; Nandi, A.K. Coupled atom transfer radical coupling and atom transfer radical polymerization approach for controlled grafting from poly(vinylidene fluoride) backbone. J. Poly. Sci. A Polym. Chem. 2014, 52, 995-1008.

6. Wang, G.W.; Huang, J.L. Versatility of radical coupling in construction of topololgical polymers. Polym. Chem. 2014, 5, 277-308.

7. Valente, C.J.; Schellenberger, A.M.; Tillman, E.S. Dimerization of poly(methyl methacrylate) chains using radical trap-assisted atom transfer radical coupling. Macromolecules 2014, 47, 2226-2232.

8. Yurteri, S.; Cianga, I.; Yagci, Y. Synthesis and characterization of $\alpha, \omega$-telechelic polymers by atom transfer radical polymerization and coupling processes. Macromol. Chem. Phys. 2003, 204, 1771-1783.

9. Sarbu, T.; Lin, K.Y.; Spanswick, J.; Gil, R.R.; Siegwart, D.J.; Matyjaszewski, K. Synthesis of hydroxy-telechelic poly(methyl acrylate) and polystyrene by atom transfer radical coupling. Macromolecules 2004, 37, 9694-9700.

10. Wang, J.S.; Matyjaszewski, K. Controlled/“living” radical polymerization atom transfer radical polymerization in the presence of transition-metal complexes. J. Am. Chem. Soc. 1995, 117, 5614-5615.

11. Kato, M.; Kamigaito, M.; Sawamoto, M.; Higashimura, T. Polymerization of methyl methacrylate with the carbon tetrachloride/dichlorotris-(triphenylphosphine)ruthenium(II)/methylaluminum bis(2,6-di-tert-butylphenoxide) initiating system: Possibility of living radical polymerization. Macromolecules 1995, 28, 1721-1723.

12. Matyjaszewski, K. Atom transfer radical polymerization (ATRP): Current status and future perspectives. Macromolecules 2012, 45, 4015-4039.

13. Patten, T.E.; Matyjaszewski, K. Copper(I)-catalyzed atom transfer radical polymerization. Acc. Chem. Res. 1999, 32, 895-903.

14. Tang, H.; Arulsamy, N.; Radosz, M.; Shen, Y.; Tsarevsky, N.V.; Braunecker, W.A.; Tang, W.; Matyjaszewski, K. Highly active copper-based catalyst for atom transfer radical polymerization. J. Am. Chem. Soc. 2006, 128, 16277-16285.

15. Voter, A.F.; Tillman, E.S. An easy and efficient route to macrocyclic polymers via intramolecular radical-radical coupling of chain ends. Macromolecules 2010, 43, 10304-10310.

16. Voter, A.F.; Tillman, E.S.; Findeis, P.; Radzinski, S.C. Synthesis of macrocyclic polymers formed via intramolecular radical trap-assisted atom transfer radical coupling. ACS Macro Lett. 2012, 1, 1066-1070.

17. Carnicom, E.M.; Tillman, E.S. Polymerization of styrene and cyclization to macrocyclic polystyrene in a one-pot, two-step sequence. React. Funct. Polym. 2014, 80, 9-14.

18. Jiang, X.Z.; Vamvakaki, M.; Narain, R. Copper-catalyzed bimolecular coupling of $\alpha, \omega$-dibromidefunctionalized poly( $\gamma$-caprolactone). Macromolecules 2010, 43, 3228-3232.

19. Huang, C.F.; Ohta, Y.; Yokoyama, A.; Yokozawa, H. Efficient low-temperature atom transfer radical coupling and its application to synthesis of well-defined symmetrical polybenzamides. Macromolecules 2011, 44, 4140-4148. 
20. Greene, A.C.; Grubbs, R.B. Nitroxide-mediated polymerization of methyl methacrylate and styrene with new alkoxyamines from 4-nitrophenyl 2-methylpropionat-2-yl radicals. Macromolecules 2010 , 43, 10320-10325.

21. Buback, M.; Egorov, M.; Gilbert, R.G.; Kaminsky, V.; Olaj, O.F.; Russell, G.T.; Vana, P.; Zifferer, G. Critically evaluated termination rate coefficients for free-radical polymerization, 1. The current situation. Macromol. Chem. Phys. 2002, 203, 2570-2582.

22. Lizotte, J.R.; Anderson, S.G.; Long, T.E. Novel dinitroxide mediating agent for stable free-radical polymerization. J. Polym. Sci. A Polym. Chem. 2004, 42, 1547-1556.

23. Domingues, K.D.; Tillman, E.S. Radical-radical coupling of polystyrene chains using AGET ATRP. J. Poly. Sci. A Polym. Chem. 2010, 48, 5737-5745.

24. Hawker, C.J.; Bosman, A.W.; Harth, E. New polymer synthesis by nitroxide mediated living radical polymerizations. Chem. Rev. 2001, 101, 3661-3688.

25. Hawker, C.J.; Barclay, G.G.; Dao, J. Radical crossover in nitroxide mediated "living" free radical polymerizations. J. Am. Chem. Soc. 1996, 46, 11467-11471.

26. Listigovers, N.A.; Georges, M.K.; Odell, P.G.; Keoshkerian, B. Narrow-polydispersity diblock and triblock copolymers of alkyl acrylates by a "living" stable free radical polymerization. Macromolecules 1996, 29, 8992-8993.

27. Fukuda, T.; Terauchi, T.; Goto, A.; Ohno, K.; Tsujii, Y.; Miyamoto, T.; Kobatake, S.; Yamada, B. Mechanisms and kinetics of nitroxide-controlledf Radical polymerization. Macromolecules 1996, 29, 6393-6398.

28. Radzinski, S.C.; Tillman, E.S. Trapping polystyrene radicals with nitrones: Synthesis of polymers with mid-chain alkoxyamine functionality. Polymer 2011, 52, 6003-6010.

(C) 2014 by the authors; licensee MDPI, Basel, Switzerland. This article is an open access article distributed under the terms and conditions of the Creative Commons Attribution license (http://creativecommons.org/licenses/by/4.0/). 